\title{
Penelusuran Persepsi Mahasiswa Atas Program Studi Akuntansi dan Minat Studi Lanjut
}

\author{
Udi Pramiudi1 Budi Setiawan²
}

\section{ABSTRAK}

Tujuan Penelitian ini adalah untuk Mengukur persepsi mahasiswa tentang kualitas program studi D3 Akuntansi dan S1 Akuntansi STIE Kesatuan serta minat melakukan studi lanjut ke jenjang S2 Akuntansi. Penelitian dilakukan di Agustus 2018 dengan 150 orang mahasiswa sebagai responden. Data dianalisis menggunakan metode Analisis Deskriptif dan Uji beda Persepsi (uji statistik Wilcoxon). Hasil penelitian menunjukkan mayoritas responden memiliki persepsi awal bahwa penyelenggaraan program D3 Akuntansi STIE Kesatuan, dipersepsikan telah memiliki kualitas yang baik. Pemberian informasi akan keunggulan D3 Akuntansi STIE Kesatuan mampu meningkatkan persepsi positif masyarakat akan kualitas D3 Akuntansi STIE Kesatuan. Mayoritas responden menyatakan berminat untuk studi lanjut pada jenjang magister. Keinginan responden untuk dapat meningkatkan kompetensi diri sesuai dengan tuntutan pekerjaan, menjadi faktor stimulus terkuat dalam membentuk minat studi lanjut.

Kata Kunci: program studi akuntansi, minat studi lanjut

\section{PENDAHULUAN}

Persaingan dunia pendidikan terus meningkat yang ditandai dengan semakin banyaknya perguruan tinggi yang menjalankan operasionalnya, termasuk dibukanya beberapa program studi pada perguruan tinggi yang sudah lama beroperasi.

Kota dan Kabupaten Bogor, sebagai kota satelit Ibukota Negara, telah memiliki lebih dari 30 perguruan tinggi baik PTN maupun PTS yang menjalankan fungsi tri dharma perguruan tinggi (Lihat Tabel 1). Jumlah tersebut, tentu menjadi tantangan tersendiri bagi Perguruan Tinggi yang bersangkutan untuk dapat menjalankan operasionalnya dan berkontribusi besar terhadap proses pembangunan bangsa dan Negara.

Tidak dipungkiri, sebagian perguruan tinggi memiliki program studi atau jurusan yang sudah tidak diminati lagi. Banyak faktor yang menyebabkan hal tersebut. Untuk mengantisipasi, perubahan minat calon mahasiswa terhadap program studi tertentu, dibutuhkan suatu penelaahan dan penelitian yang mendalam tentang berbagai hal yang menjadi penyebabnya.

Membangun minat studi masyarakat pada suatu program studi di setiap jenjang pendidikan akan sangat dipengaruhi oleh informasi dan pengalaman yang dimilikinya. Sejak diberlakukannya peraturan pemerintah tentang wajibnya jenjang pendidikan
1. Program Studi Akuntansi, Sekolah Tinggi llmu Ekonomi Kesatuan, Jl. Ranggagading No. 1 Bogor Jawa Barat 16123, Indonesia

2. Program Studi Manajemen, Sekolah Tinggi llmu Ekonomi Kesatuan, Jl. Ranggagading No. 1 Bogor Jawa Barat 16123, Indonesia

\section{EMail}

udi.pramiudi@stiekesatuan.a c.id

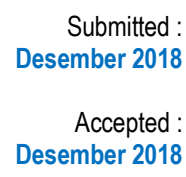

JAS-PT

JURNAL ANAUSIS SISTEM PENDIDIKAN TINGG

ISSN 2580 - 5339

eISSN 2620 - 5718

Volume 2

Nomor 2

DESEMBER 2018

Hal $103-113$ 
strata 2 sebagai jenjang pendidikan minimal bagi Tenaga Pendidik di Perguruan Tinggi, maka jenjang pendidikan magister menjadi program studi yang sangat diminati.

Sekolah Tinggi Ilmu Ekonomi Kesatuan sebagai sebuah perguruan tinggi swasta di Bogor melakukan studi kelayakan dengan menelusuri minat masyarakat lulusan sarjana terhadap program studi S2 Akuntansi yang akan diselenggarakan. Pengukuran minat tersebut dilakukan dengan melakukan evaluasi persepsi mahasiswa terhadap program studi D3 Akuntansi dan program studi S1 Akuntansi yang telah lebih awal diselenggarakan.

Tujuan penelitian ini adalah sebagai berikut :

a. Mengukur persepsi mahasiswa tentang kualitas program studi D3 Akuntansi

b. Mengukur persepsi mahasiswa tentang kualitas program studi S1 Akuntansi

c. Mengukur minat mahasiswa untuk melakukan studi lanjut ke jenjang magister

d. Mengukur minat mahasiswa untuk melakukan studi lanjut ke program studi S2 Akuntansi

\section{TINJAUAN PUSTAKA}

Minat

Apabila seseorang menaruh perhatian terhadap sesuatu, maka minat akan menjadi motif yang kuat untuk berhubungan secara lebih aktif dengan sesuatu yang menarik minatnya. Minat akan semakin bertambah jika disalurkan dalam suatu kegiatan. Keterikatan dengan kegiatan tersebut akan semakin menumbuhkembangkan minat.

Guilford (dalam Munandir, 1996:146) menyatakan minat adalah kecenderungan tingkah laku umum seseorang untuk tertarik kepada sekelompok hal tertentu. Menurut Birmingham (dalam Munandir, 1996:146), berpendapat bahwa minat adalah kecenderungan orang untuk tertarik dalam suatu pengalaman dan untuk terus demikian, sementara aversi (kebencian, keengganan) adalah kecenderungan untuk berpaling dari pengalaman lain. Kecenderunagan itu tetap bertahan sekalipun seseorang sibuk mengerjakan hal lain. Kegiatan yang diikuti seseorang karena kegiatan itu menarik baginya, merupakan perwujudan minatnya.

Orang yang berminat pada sesuatu, memberikan perhatian kepadanya, mencarinya, mengarahkan dirinya kepadanya, atau berusaha mencapai atau memperoleh sesuatu yang bernilai baginya. Minat menunjukkan kemungkinan apa saja yang akan dilakukan orang, bukan bagaimana ia akan melakukan hal itu atau bagaimana ia baiknya ia melakukan hal itu.

\section{Arti Penting Minat dalam Pelaksanaan Studi}

Minat berarti sibuk, tertarik, atau terlibat sepenuhnya dengan sesuatu kegiatan karena menyadari pentingnya kegiatan itu. Menurut The Liang Gie (1994:28-29), minat studi merupakan salah satu unsur sangat penting dari sikap akademik mahasiswa dalam kaitannya dengan penyelenggaraan pendidikan di perguruan tinggi. Minat yang besar

JAS-PT

ISSN $2580-5339$ eISSN $2620-5718$

Volume 2

Nomor 2

DESEMBER 2018

Hal $103-113$

FORUM DOSEN INDONESIA terhadap kegiatan pikiran untuk menggali keterangan dan mencapai pemahaman tentang segenap cabang ilmu dalam bidang studinya adalah bagian dari sikap akademik mahasiswa Indonesia.

Memilih jurusan pada dasarnya merupakan sebuah proses yang sudah dimulai sejak masa anak-anak. Kesempatan, stimulasi, pengalaman apa saja yang diberikan pada anak sejak kecil secara optimum dan konsisten, itu akan menjadi bekal, modal dan fondasi minat dan bakatnya. Makin banyak dan luas exposure-nya, makin anak tahu 
banyak tentang dirinya, tapi makin sedikit exposure-nya, makin sedikit juga pengetahuan anak tentang dirinya.

Ada beberapa hal yang perlu diperhatikan dalam melakukan pemilihan jurusan agar jurusan yang dipilih tepat, yaitu mencari informasi secara detil mengenai jurusan yang diminati. Sebelum memilih jurusan, hendaknya anak punya informasi yang luas dan detil, mulai dari ilmunya, mata kuliahnya, praktek lapangan, dosen, universitasnya, komunitas sosialnya, kegiatan kampusnya, biaya, alternatif profesi kerja, kualitas alumninya, dan lain-lain.

Menyadari bahwa jurusan yang dipilih hanya merupakan salah satu anak tangga awal dari proses pencapaian karir. Anak perlu tahu realitanya, bahwa jurusan yang dipilih tidak menjamin kesuksesan masa depannya. Jangan dikira bahwa dengan kuliah di jurusan tersebut maka hidupnya kelak pasti sukses seperti yang diiklankan.

Jurusan yang dipilih sebaiknya sesuai dengan kemampuan dan minat siswa yang bersangkutan. Jika seorang siswa memilih jurusan sesuai dengan kemampuan dan minatnya, maka dirinya akan mampu bertahan dalam menghadapi kesulitan-kesulitan selama kuliah, namun jika dirinya tidak memiliki kemampuan dan minat dalam jurusan yang dipilih, bisa mempengaruhi motivasi belajar

\section{METODOLOGI PENELITIAN}

Metode penelitian yang digunakan adalah analisis deskriptif kuantitatif. Populasi penelitian ini adalah mahasiswa D3 dan Akuntansi pada STIE Kesatuan, STIE Kalpataru, UNAS PASIM, STIE Dewantara, Institut IImu Sosial dan Politik, Universitas Pramita Indonesia dan Universitas Terbuka dengan sampel berjumlah 150 orang mahasiswa. Penelitian dilaksanakan pada Agustus 2018. Metode pengambilan sampel yang digunakan adalah Stratified random sampling. Metode analisis yang digunakan adalah 1) Analisis Deskriptif, 2) Uji beda Persepsi (uji statistik Wilcoxon).

\section{HASIL DAN PEMBAHASAN}

\section{Karakteristik Responden}

Tabel 1 Distribusi Frekuensi Responden Berdasarkan Jenis Kelamin

\begin{tabular}{lcc}
\multicolumn{1}{c}{ Jenis Kelamin } & Frekuensi & Prosentase \\
\hline Wanita & 90 & 60,0 \\
Laki-laki & 60 & 40,0 \\
Total & 150 & 100,0 \\
\hline
\end{tabular}

Sumber: Data Primer Diolah, 2018

Mengacu pada Tabel 1 tersebut di atas maka dapat diketahui bahwa responden penelitian ini terdiri dari $60 \%$ responden wanita dan $40 \%$ responden pria. Sehingga dengan demikian responden wanita lebih mendominasi penelitian ini dibandingkan pria, dengan selisih proporsi yang cukup nyata sebesar $20 \%$.

Mengacu pada Tabel 2 tersebut di atas diketahui bahwa rata-rata usia responden penelitian adalah 27,03 tahun, dengan usia terendah 21 tahun dan usia tertinggi 42 tahun. Nilai simpangan baku sebesar 4,904 tahun mengindikasikan adanya variabilitas data usia responden yang cukup besar, dengan rentang usia 21 tahun. Frekuensi usia responden adalah sebagaimana disajikan pada tabel 3 berikut ini.

\footnotetext{
JAS-PT

JURNAL ANALISIS SISTEM PENDIDIKAN TINGGI ISSN $2580-5339$ eISSN $2620-5718$

Volume 2 Nomor 2 DESEMBER 2018 Hal $103-113$

FORUM DOSEN INDONESIA
} 


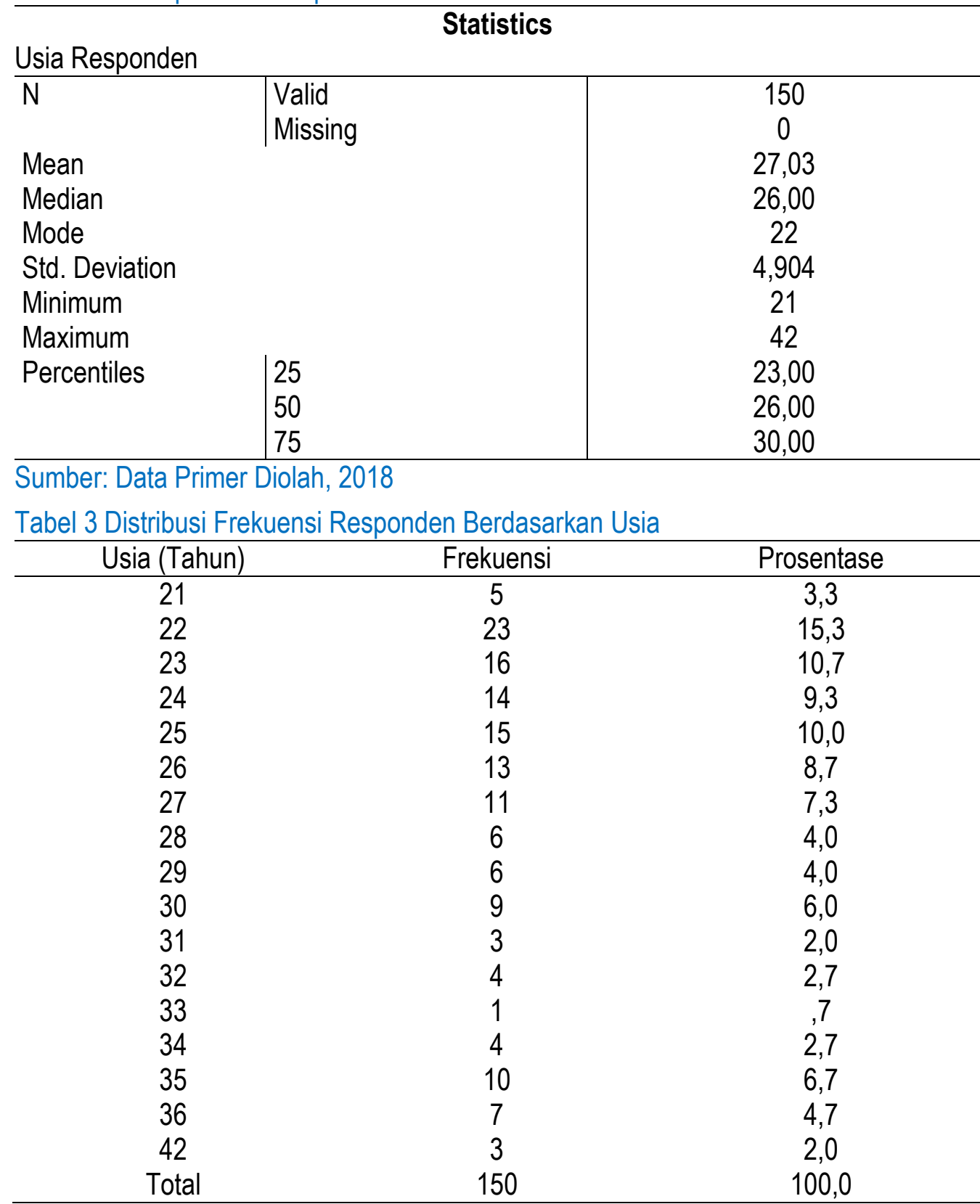

\section{Sumber: Data Primer Diolah, 2018}

Mengacu pada tabel 3 tersebut di atas maka dapat diketahui bahwa responden penelitian lebih didominasi pada responden berusia 22 sampai 27 tahun. Sehingga perolehan nilai rata-rata sebesar 27,03 tahun dan nilai tengah sebesar 26 tahun telah mampu menggambarkan dengan baik dari pemusatan data.

JAS-PT

JURNAL ANALISIS SISTEM PENDIDIKAN TINGG ISSN $2580-5339$ elSSN $2620-5718$

Volume 2

Nomor 2

DESEMBER 2018

Hal $103-113$

\section{Latar Belakang Pendidikan Jenjang Sarjana Para Responden}

Latar belakang pendidikan sarjana dari responden penelitian berdasarkan nama perguruan tinggi dan jurusan yang diambil, adalah sebagaimana disajikan pada tabel 4 dan tabel 5.

Mengacu pada tabel 4 tersebut di atas dapat diketahui bahwa responden penelitian ini didominasi oleh responden lulusan dari STIE Kesatuan, disusul dari STIE Dewantara, 
Universitas Nasional Pasim, dan STIE Kalpataru. Sedangkan apabila ditinjau dari latar belakang jurusan, hasilnya sebagaimana disajikan pada tabel berikut ini.

Tabel 4 Latar Belakang Lulusan Perguruan Tinggi

\begin{tabular}{lcc}
\hline \multicolumn{1}{c}{ Lulusan Perguruan Tinggi } & Frekuensi & Prosentase \\
\hline Institut Ilmu Sosial dan Politik & 3 & 2,0 \\
STIE Dewantara & 22 & 14,7 \\
STIE Kalpataru & 12 & 8,0 \\
STIE Kesatuan & 96 & 64,0 \\
Unas PASIM & 15 & 10,0 \\
Universitas Pramita Indonesia & 1 &, 7 \\
UT & 1 &, 7 \\
Total & 150 & 100,0
\end{tabular}

Sumber: Data Primer Diolah, 2018

Tabel 5 Latar Belakang Program Studi Para Responden

\begin{tabular}{|c|c|c|}
\hline Program Studi & Frekuensi & Prosentase \\
\hline Akuntansi & 59 & 39,3 \\
\hline Komunikasi & 3 & 2,0 \\
\hline Manajemen & 88 & 58,7 \\
\hline Total & 150 & 100,0 \\
\hline
\end{tabular}

Sumber: Data Primer Diolah, 2018

Mengacu pada tabel 5 tersebut di atas maka dapat diketahui bahwa responden penelitian ini didominasi oleh responden dengan latar belakang pendidikan sarjana ekonomi jurusan manajemen dan akuntansi. Untuk tahun kelulusan sarjana dari responden penelitian, adalah sebagaimana disajikan pada tabel berikut ini.

Tabel 6 Tahun Kelulusan Sarjana Para Responden

\begin{tabular}{lcc}
\hline \multicolumn{1}{c}{ Tahun Lulus } & Frekuensi & Prosentase \\
\hline$<$ Th. 2000 & 1 &, 7 \\
Th. $2000-2004$ & 14 & 9,3 \\
Th. $2005-2009$ & 23 & 15,3 \\
Th. $2010-2014$ & 52 & 34,7 \\
Th. 2015 & 60 & 40,0 \\
Total & 150 & 100,0 \\
\hline
\end{tabular}

Sumber: Data Primer Diolah, 2018

Mengacu pada tabel 6 tersebut di atas maka dapat diketahui bahwa responden penelitian ini didominasi oleh lulusan tahun 2015 dan kemudian diikuti oleh lulusan tahun 2010 sampai tahun 2014. Hal ini mendukung deskripsi data usia responden yang memiliki rata-rata usia 27,03 tahun sehingga dengan kata lain potensi untuk melanjutkan pendidikan tingkat magister dapat terbuka lebih luas.

Motivasi orang untuk melanjutkan pendidikan ke jenjang magister bisa sangat beragam. Ada yang didorong karena tuntutan pekerjaan, ada juga yang karena ingin meraih suatu profesi yang diidamkan, dengan harapan memperoleh penghasilan yang lebih baik dari saat ini.

JAS-PT

JURNAL ANALISIS SISTEM PENDIDIKAN TINGG ISSN $2580-5339$ eISSN $2620-5718$

Volume 2

Nomor 2

DESEMBER 2018

Hal $103-113$

FORUM DOSEN INDONESIA 
pekerjaan responden saat ini memiliki keterkaitan dengan ilmu akuntansi ataukah tidak. Hasilnya sebagaimana disajikan pada tabel di bawah ini.

Tabel 7 Latar Belakang Pekerjaan Responden

\begin{tabular}{lcc}
\hline \multicolumn{1}{c}{ Pekerjaan } & Frekuensi & Prosentase \\
\hline Lainnya & 18 & 12,0 \\
Pegawai Swasta & 117 & 78,0 \\
Pegawai Negeri & 2 & 1,3 \\
Wirausaha & 13 & 8,7 \\
Total & 150 & 100,0
\end{tabular}

Sumber: Data Primer Diolah, 2018

Tabel 8 Keterkaitan IImu Akuntansi dengan Pekerjaan saat Ini

\begin{tabular}{lcc}
\hline Keterkaitan Keilmuan dengan Pekerjaan & Frekuensi & Prosentase \\
\hline Tidak Tahu & 8 & 5,3 \\
Tidak Terkait & 30 & 20,0 \\
Cukup Terkait & 26 & 17,3 \\
Terkait & 56 & 37,3 \\
Sangat Terkait & 30 & 20,0 \\
Total & 150 & 100,0
\end{tabular}

Sumber: Data Primer Diolah, 2018

Mengacu pada tabel 8 tersebut di atas maka dapat diketahui bahwa mayoritas responden menyatakan pekerjaannya saat ini memiliki keterkaitan dengan bidang ilmu akuntansi. Untuk melengkapi informasi akan pekerjaan, maka perlu ditelaah rata-rata penghasilan per bulan responden. Hasilnya adalah sebagaimana disajikan pada tabel berikut ini.

Tabel 9 Rata-rata Penghasilan per Bulan

\begin{tabular}{lcc}
\hline \multicolumn{1}{c}{ Penghasilan (Rp) } & Frekuensi & Prosentase \\
\hline < Rp.2.500.000 & 17 & 11,3 \\
Rp. 2.500.000 - Rp. 3.499.999 & 37 & 24,7 \\
Rp. 3.500.000 - Rp. 4.999.999 & 43 & 28,7 \\
Rp. 5.000.000 - Rp. 7.499.999 & 37 & 24,7 \\
Rp. 7.500.000 - Rp. 9.999.999 & 9 & 6,0 \\
>= Rp. 10.000.000 & 7 & 4,7 \\
Total & 150 & 100,0 \\
\hline
\end{tabular}

Sumber: Data Primer Diolah, 2018

Mengacu pada tabel 9 tersebut di atas maka responden penelitian tersebar cukup proporsional pada rata-rata penghasilan Rp.2.500.000 - Rp. 3.4.999.999 hingga Rp. 5.000.000 - Rp. 7.499.999. Dengan demikian dapat menjadi target konsumen yang cukup tepat, dalam memasarkan program studi magister Akuntansi. Besar minat responden untuk studi lanjut ke jenjang magister adalah sebagaimana disajikan pada tabel berikut ini.

JAS-PT

JURNAL ANALISIS SISTEM PENDIDIKAN TINGGI ISSN $2580-5339$ eISSN $2620-5718$ Volume 2 Nomor 2 DESEMBER 2018 Hal $103-113$

FORUM DOSEN INDONESIA

\section{Pengetahuan Responden akan STIE Kesatuan}

Mayoritas responden $(94,7 \%)$ menyatakan telah mengetahui atau mengenal akan STIE Kesatuan, dan hanya $5,3 \%$ responden saja yang menyatakan belum mengetahui atau belum mengenal akan kampus STIE Kesatuan. Meskipun mayoritas responden menyatakan telah mengenal akan STIE Kesatuan, namun demikian terkait program magister Akuntansi yang akan dibuka, perlu ditelaah terlebih dahulu persepsi awal responden akan kualitas D3 Akuntansi dan S1 Akuntansi STIE Kesatuan. 
Persepsi awal responden akan kualitas penyelenggaraan program D3 Akuntansi pada STIE Kesatuan, yakni tanpa adanya perlakuan pemberian informasi keunggulan program D3 Akuntansi, memiliki hasil sebagaimana disajikan pada tabel berikut.

Tabel 10 Persepsi Awal Responden akan Kualitas D3 Akuntansi STIE Kesatuan

\begin{tabular}{|c|c|c|}
\hline Persepsi & Frekuensi & Prosentase \\
\hline Biasa Saja & 19 & 12,7 \\
\hline Baik & 92 & 61,3 \\
\hline Sangat Baik & 39 & 26,1 \\
\hline Total & 150 & 100,0 \\
\hline
\end{tabular}

Sumber: Data Primer Diolah, 2018

Mengacu pada tabel 10 tersebut diketahui bahwa mayoritas responden menyatakan bahwa penyelenggaraan program D3 Akuntansi pada STIE Kesatuan, dipersepsikan telah memiliki kualitas yang baik. Persepsi awal diberikan responden sebelum adanya perlakuan, yakni tidak diinformasikannya segala keunggulan pada program D3 Akuntansi STIE Kesatuan. Perlakuan kemudian diberikan, yakni dengan memberikan informasi akan keunggulan program D3 Akuntansi STIE Kesatuan.

Persepsi responden akan kualitas D3 Akuntansi STIE Kesatuan, pasca diberikan perlakuan berupa pemberian informasi adalah sebagaimana disajikan pada tabel berikut ini.

Tabel 11 Persepsi Responden akan Kualitas D3 Akuntansi STIE Kesatuan pasca Perlakuan

\begin{tabular}{|c|c|c|}
\hline Persepsi & Frekuensi & Prosentase \\
\hline Biasa Saja & 18 & 12,0 \\
\hline Baik & 101 & 67,3 \\
\hline Sangat Baik & 21 & 14,0 \\
\hline Tidak Tahu & 10 & 6,0 \\
\hline Total & 150 & 100,0 \\
\hline
\end{tabular}

Sumber: Data Primer Diolah, 2018

Mengacu pada tabel tersebut diketahui bahwa terjadi peningkatan persepsi kualitas yang baik akan penyelenggaraan program D3 Akuntansi pada STIE Kesatuan. Perlakuan yang diberikan dapat memberikan perubahan hasil yang nyata. Untuk dapat memverifikasi secara statistik perbedaan persepsi tersebut, maka perlu dilakukan uji statistik Wilcoxon dengan hasil sebagai berikut.

Wilcoxon Signed Ranks Test

\begin{tabular}{llrrr} 
& \multicolumn{4}{c}{ Ranks } \\
Persepsi awal & Negative Ranks & $12^{\mathrm{a}}$ & 12,04 & Mean Rank \\
Kualitas D3 - & Positive Ranks & $7^{\mathrm{b}}$ & 6,50 & 444,50 \\
Persepsi Kualitas D3 & Ties & $111^{\mathrm{c}}$ & & \\
akhir & Total & 130 & &
\end{tabular}

a. Persepsi awal Kualitas D3 < Persepsi Kualitas D3 after

b. Persepsi awal Kualitas D3 > Persepsi Kualitas D3 after

c. Persepsi awal Kualitas D3 $=$ Persepsi Kualitas D3 after

Test Statisticsa

Persepsi awal Kualitas D3 - Persepsi Kualitas D3 after

Z

Asymp. Sig. (2-tailed)

a. Wilcoxon Signed Ranks Test

b. Based on positive ranks. $-2,060^{b}$

, 039
JAS-PT

JURNAL ANALISIS SISTEM PENDIDIKAN TINGGI ISSN $2580-5339$ eISSN $2620-5718$

Volume 2 Nomor 2 DESEMBER 2018 Hal $103-113$

FORUM DOSEN INDONESIA 
Mengacu pada hasil Wilcoxon Signed Ranks Test tersebut di atas diketahui nilai Asymp. Sig (2-tailed) sebesar 0,039 < 0,05 sehingga dengan demikian keputusannya adalah terdapat perbedaan yang nyata, sebelum dan sesudah perlakuan. Dengan kata lain, pemberian informasi akan keunggulan D3 Akuntansi STIE Kesatuan mampu meningkatkan persepsi positif masyarakat akan kualitas D3 Akuntansi STIE Kesatuan.

Persepsi responden tidak hanya diukur pada jenjang D3 Akuntansi, namun juga pada jenjang S1 Akuntansi. Seperti halnya pada jenjang D3, responden diukur persepsinya sebelum dan sesudah perlakuan. Persepsi awal responden akan kualitas S1 Akuntansi STIE Kesatuan adalah sebagaimana disajikan pada tabel berikut ini.

Tabel 12 Persepsi Awal Responden akan Kualitas S1 Akuntansi STIE Kesatuan

\begin{tabular}{|c|c|c|}
\hline Persepsi & Frekuensi & Prosentase \\
\hline Biasa Saja & 14 & 9,3 \\
\hline Baik & 74 & 49,3 \\
\hline Sangat Baik & 47 & 31,3 \\
\hline Tidak Tahu & 15 & 10,1 \\
\hline Total & 150 & 100,0 \\
\hline
\end{tabular}

Sumber: Data Primer Diolah, 2018

Mengacu pada tabel 12 tersebut di atas, maka dapat disimpulkan bahwa penyelenggaraan program S1 Akuntansi pada STIE Kesatuan telah mendapatkan persepsi kualitas yang sangat baik $(34,8 \%)$ dan baik $(49,3 \%)$ dari responden. Persepsi kualitas S1 Akuntansi setelah diberikan perlakuan sebagaimana halnya pada program D3 Akuntansi, adalah sebagaimana disajikan pada tabel berikut ini.

Tabel 13 Persepsi Responden akan Kualitas S1 Akuntansi STIE Kesatuan pasca Perlakuan

\begin{tabular}{|c|c|c|}
\hline Persepsi & Frekuensi & Prosentase \\
\hline Biasa Saja & 11 & 7,3 \\
\hline Baik & 82 & 54,7 \\
\hline Sangat Baik & 53 & 35,3 \\
\hline Tidak Tahu & 4 & 2,7 \\
\hline Total & 150 & 100,0 \\
\hline
\end{tabular}

Sumber: Data Primer Diolah, 2018

Mengacu pada tabel 13 tersebut diketahui bahwa terjadi peningkatan persepsi kualitas yang baik akan penyelenggaraan program S1 Akuntansi pada STIE Kesatuan. Perlakuan yang diberikan dapat memberikan perubahan hasil yang nyata. Untuk dapat memverifikasi secara statistik perbedaan persepsi tersebut, maka perlu dilakukan uji statistik Wilcoxon dengan hasil sebagai berikut.

Wilcoxon Signed Ranks Test

\section{Ranks}

$\begin{array}{llrrr} & & \text { N } & \text { Mean Rank } & \text { Sum of Ranks } \\ \text { Persepsi awal kualitas S1 - Negative Ranks } & 18^{\mathrm{a}} & 13,50 & 243,00 \\ \text { Persepsi Kualitas S1 akhir } & \text { Positive Ranks } & 6^{\mathrm{b}} & 9,50 & 57,00 \\ & \text { Ties } & 111^{\mathrm{c}} & & \\ & \text { Total } & 135 & & \end{array}$

a. Persepsi awal kualitas S1 < Persepsi Kualitas S1 after

b. Persepsi awal kualitas S1 > Persepsi Kualitas S1 after

c. Persepsi awal kualitas S1 = Persepsi Kualitas S1 after

FORUM DOSEN INDONESIA 


\section{Test Statistics ${ }^{\mathrm{a}}$}

Persepsi awal kualitas S1 - Persepsi Kualitas S1 after

Asymp. Sig. (2-tailed)

a. Wilcoxon Signed Ranks Test

b. Based on positive ranks.

Mengacu pada hasil Wilcoxon Signed Ranks Test tersebut di atas diketahui nilai Asymp. Sig (2-tailed) sebesar 0,005 $<0,05$ sehingga dengan demikian keputusannya adalah terdapat perbedaan yang nyata, sebelum dan sesudah perlakuan. Dengan kata lain, pemberian informasi akan keunggulan S1 Akuntansi STIE Kesatuan mampu meningkatkan persepsi positif masyarakat akan kualitas S1 Akuntansi STIE Kesatuan.

Minat Studi Lanjut pada Program Magister Akuntansi STIE Kesatuan

Tabel 14 Minat Studi Lanjut ke Jenjang Magister

\begin{tabular}{lcc}
\hline \multicolumn{1}{c}{ Persepsi } & Frekuensi & Prosentase \\
\hline Tidak Berminat & 8 & 5,3 \\
Biasa Saja & 32 & 21,3 \\
Besar & 63 & 42,0 \\
Sangat Besar & 47 & 31,3 \\
Total & 150 & 100,0 \\
\hline
\end{tabular}

Sumber: Data Primer Diolah, 2018

Mengacu pada tabel 14 tersebut di atas maka dapat diketahui bahwa minat studi lanjut responden pada jenjang magister didominasi pada minat yang besar dan sangat besar. Hal ini menjadi informasi positif bagi STIE Kesatuan untuk dapat menjadikan minat studi lanjut tersebut, sebagai target konsumen dalam pemasaran jenjang magister akuntansi.

Minat studi lanjut pada program Magister Akuntansi STIE Kesatuan adalah sebagaimana disajikan pada Tabel 15 berikut.

Tabel 15 Minat Studi Lanjut pada Program Magister Akuntansi STIE Kesatuan

\begin{tabular}{lcc}
\hline \multicolumn{1}{c}{ Persepsi } & Frekuensi & Prosentase \\
\hline Tidak Berminat & 14 & 9,3 \\
Ragu-ragu & 27 & 18,0 \\
Cukup Berminat & 33 & 22,0 \\
Berminat & 39 & 26,0 \\
Sangat Berminat & 26 & 17,3 \\
Tidak Tahu & 11 & 7,3 \\
Total & 150 & 100,0 \\
\hline
\end{tabular}

Sumber: Data Primer Diolah, 2018

Mengacu pada tabel 15 tersebut di atas maka dapat diketahui bahwa terdapat sebaran data yang cukup proporsional pada setiap kategori. Apabila dilihat dari kategori berminat dan sangat berminat sebagai landasan target konsumen, maka terdapat target pasar sasaran sebesar $43,3 \%$ dari responden untuk dapat melanjutkan studi pada jenjang magister Akuntansi STIE Kesatuan.

Keinginan responden untuk dapat meningkatkan kompetensi diri sesuai dengan tuntutan pekerjaan, menjadi faktor stimulus terkuat dalam membentuk minat studi lanjut.

JAS-PT

JURNAL ANALISIS SISTEM PENDIDIKAN TINGG

ISSN $2580-5339$ eISSN $2620-5718$

Volume 2

Nomor 2

DESEMBER 2018

Hal $103-113$

FORUM DOSEN INDONESIA 


\section{PENUTUP}

\section{Simpulan}

Berapa kesimpulan yang dapat ditarik dari hasil penelitian ini adalah sebagai berikut:

1. Mayoritas responden memiliki persepsi awal bahwa penyelenggaraan program D3 Akuntansi STIE Kesatuan, dipersepsikan telah memiliki kualitas yang baik. Pemberian informasi akan keunggulan D3 Akuntansi STIE Kesatuan mampu meningkatkan persepsi positif masyarakat akan kualitas D3 Akuntansi STIE Kesatuan

2. Pada Tahap Persepsi Awal Program Studi S1 Akuntansi STIE Kesatuan telah mendapatkan persepsi kualitas yang sangat baik $(34,8 \%)$ dan baik $(49,3 \%)$ dari responden. Pemberian informasi akan keunggulan S1 Akuntansi STIE Kesatuan mampu meningkatkan persepsi positif masyarakat akan kualitas S1 Akuntansi STIE Kesatuan.

3. Minat studi lanjut responden pada jenjang magister didominasi pada minat yang besar dan sangat besar

4. Separuh dari responden menyatakan berminat untuk melakukan studi lanjut ke program studi S2 Akuntansi STIE Kesatuan. Keinginan responden untuk dapat meningkatkan kompetensi diri sesuai dengan tuntutan pekerjaan, menjadi faktor stimulus terkuat dalam membentuk minat studi lanjut.

\section{Saran}

Berdasarkan data yang telah diolah, maka penulis memberikan saran-saran sebagai berikut :

1. Pemberian informasi tentang keunggulan Program Studi menjadi penting dilakukan agar meningkatkan motivasi terhadap mahasiswa untuk mengambil keputusan studi lanjut pada jenjang pendidikan yang lebih tinggi.

2. Kesesuaian program pembelajaran dengan pekerjaan para mahasiswa menjadi pertimbangan penting yang harus diperhatikan penyelenggara program studi.

\section{DAFTAR PUSTAKA}

Arikunto, Suharsimi. 2006a. Dasar-dasar Evaluasi Pendidikan. Jakarta: PT Bumi Aksara.

Anamofa, J.N., 2017. Analisis Pengaruh Gaya dan Situasi Kepemimpinan Terhadap Iklim Kerja Universitas Halmahera. JAS-PT Jurnal Analisis Sistem Pendidikan Tinggi, 1(2), pp.53-62.

Bimo, Walgito. 2002. Pengantar Psikologi Umum. Yogyakarta: Andi Yogyakarta.

Cahyana, R. and Sagala, I., 2017. Model Sistem Perubahan dalam Lingkup Program

JAS-PT

ISSN $2580-5339$ elSSN $2620-5718$ Volume 2

Nomor 2

DESEMBER 2018

Hal $103-113$

FORUM DOSEN INDONESIA Sarjana. JAS-PT Jurnal Analisis Sistem Pendidikan Tinggi, 1(1), pp.47-52.

Hadi, Sutrisno.2002. Metodologi Research. Yogyakarta: Andi Yogyakarta.

KUSWANTO, K., 2017. PENGARUH GAYA KEPEMIMPINAN TRANSFORMATIF TERHADAP KINERJA PEGAWAI STKIP PGRI LAMONGAN. JAS-PT Jurnal Analisis Sistem Pendidikan Tinggi, 1(2), pp.63-68.

Mardalis. 2004. Metode Penelitian Suatu Pendekatan Proposal. Jakarta: Bumi Aksara. 
Mohd Noriah, dkk. Kecerdasan Emosi Dan Hubungannya Dengan Nila Kerja. Jurnal Teknologi, 39(E) Dis. 2003: 77-84.

Munandir. 1996. Program Bimbingan Karier di Sekolah. Jakarta: Direktur Jenderal Pendidikan Tinggi.

Prasetyo, Bambang. 2005. Metode Penelitian Kuantitatif : Teori dan Aplikasinya. Jakarta: PT Raja Grafindo Persada.

Pratiwi, Wulandari. Universitas Negeri dan Jurusan yang paling diminati. Online http://community.gunadarma.ac.id/archive/mod_blog/id_9808/title_tugas-1riset-akuntansi-penelitian/

Siagian, P Sondang. 1995. Teori Motivasi Dan Aplikasinya. Jakarta: PT Rineka Cipta.

Utami. 2007. Faktor-Faktor Yang Mempengaruhi Minat Berwiraswasta (Studi Deskriptif Pada Usahawan Rental Komputer Di Sekaran Gunung Pati Semarang). Skripsi: Universitas Negeri Semarang.

Slameto. 2003. Belajar dan Faktor-Faktor yang Mempengaruhinya. Jakarta Rineka Cipta.

Sugiyono. 2007. Statistika Untuk Penelitian. Bandung: Alfabeta.

Sujdana. 2002. Metoda Statistika. Bandung: Tarsito.

Sukardi. 2003. Metode Penelitian Pendidikan Kompetensi dan Prakteknya. Jakarta: Bumi Aksara.

The Liang Gie. 1994. Cara Belajar yang Efisien. Yogyakarta: PUBIB (Pusat Belajar IImu Berguna).

1995. Cara Belajar yang Efisien. Yogyakarta: PUBIB (Pusat Belajar IImu Berguna).

Vivipermata. 2008. Apa Itu Minat. Online http://vivipermata.blog friendster.com2008/08/28/

Zuriah, Nurul. 2009. Metodologi Penelitian Sosial dan Pendidikan. Jakarta: PT Bumi Aksara. 